\title{
Estado e Sociedade: os direitos das pessoas com deficiência e os respectivos deveres do Estado
}

State and Society: the rights of persons with disabilities and the respective duties of the State

Wellington Anselmo Martins

Universidade Estadual Paulista Júlio de Mesquita

Filho, UNESP, Bauru/SP, Brasil.

Resumo Este artigo, a partir de uma hipótese jurídica inclusiva, trata do conceito de pessoa com deficiência dentro do ordenamento jurídico pátrio, tendo como base principiológica os Direitos Humanos e as noções contemporâneas de linguagem inclusiva. É feita uma revisão de literatura com o objetivo de esclarecer e promover a dignidade da pessoa humana aplicada às necessidades especiais dessa minoria social em estudo. Ainda um levantamento histórico acerca de nomenclaturas é exposto ao longo deste trabalho, a fim de aumentar a visibilidade do debate, que entrelaça as ideias de sociedade inclusiva e de adequação linguístico-discursiva. Por fim, na ordem prática, salientam-se os direitos sociais já garantidos às pessoas com deficiência e, em decorrência disso, os deveres que o Estado tem de cumprir para o pleno exercício de sua característica democrática.

Palavras-chave: Direitos Humanos. Deveres do Estado. Sociedade Inclusiva. Estatuto da Pessoa com Deficiência.

Abstract This article deals with the concept of persons with disabilities within the national legal system, based on the principles of Human Rights and the contemporary notions of inclusive language. A literature 
review is made with the purpose of clarifying and promoting the dignity of the human person applied to the special needs of this social minority under study. Yet a historical survey of nomenclatures is exposed throughout this work, in order to increase the visibility of the debate that interweaves the ideas of inclusive society and linguistic-discursive adequacy. Finally, in the practical order, the social rights already guaranteed to people with disabilities and, as a result, the duties that the State has to fulfill for the full exercise of its democratic characteristic are highlighted.

Keywords: Human Rights. Duties of the State. Inclusive society. Statute of the Person with Disabilities.

\section{INTRODUÇÃO}

Esta pesquisa procura apresentar o conceito jurídico atual de pessoa com deficiência, a partir de uma revisão de literatura especializada, com foco na promoção deste debate à luz dos princípios humanistas. Assim, introdutoriamente, cita-se a Lei Brasileira de Inclusão ou Estatuto da Pessoa com Deficiência, Lei n. ${ }^{\circ} 13.146$, de 6 de julho de 2015, que entrou em vigor no início de 2016, e em seu artigo $2^{\circ}$ define pessoa com deficiência, seguindo a orientação da Convenção sobre os Direitos das Pessoas com Deficiência, da Organização das Nações Unidas - ONU (2007):

Considera-se pessoa com deficiência aquela que tem impedimento de longo prazo de natureza física, mental, intelectual ou sensorial, o qual, em interação com uma ou mais barreiras, pode obstruir sua participação plena e efetiva na sociedade em igualdade de condições com as demais pessoas.

Ou seja, o Estatuto da Pessoa com Deficiência, como doravante será chamada a lei em questão, apresenta uma definição específica ao salientar que pessoas com deficiência são as que têm impedimento de longo prazo, descartando assim desta definição as pessoas que, de modo efêmero, de curto prazo, tenham também limitações diversas. 
Essa definição apresentada pelo Estatuto é também uma definição ampla, porque não descarta qualquer tipo de limitação que pode acometer um indivíduo, por isso reconhece como pessoa com deficiência todas as que têm impedimentos físicos, mentais, intelectuais ou sensoriais.

Resta salientar que a definição contida no artigo $2^{\circ}$ encerra o conceito abordando o tema da igualdade, princípio fundamental previsto no artigo $5^{\circ}$ da Constituição Federal. Isso implica reconhecer que são consideradas pessoas com deficiência, segundo o Estatuto, todos os que, em comparação com as pessoas sem deficiência e em decorrência das barreiras sociais, não podem usufruir daquilo que o texto legal chama de "participação plena e efetiva na sociedade".

\section{PrincíPIO da IGUALdAde APLICAdo A PESSOAS COM DEFICIÊNCIA}

Ao apresentar o texto da Convenção sobre os Direitos das Pessoas com Deficiência, da ONU, de 30 de março de 2007, fonte inspiradora do Estatuto, o então Secretário Nacional de Promoção dos Direitos da Pessoa com Deficiência no Brasil, Antônio José Ferreira (2011, p. 15), reafirma pontos humanísticos essenciais para a definição de pessoa com deficiência:

Pessoas com deficiência são, antes de mais nada, pessoas. Pessoas como quaisquer outras, com protagonismos, peculiaridades, contradições e singularidades. Pessoas que lutam por seus direitos, que valorizam o respeito pela dignidade, pela autonomia individual, pela plena e efetiva participação e inclusão na sociedade e pela igualdade de oportunidades, evidenciando, portanto, que a deficiência é apenas mais uma característica da condição humana.

Esse apelo à dignidade humana, fundamento da República Federativa do Brasil, conforme artigo $1^{\circ}$, inciso III, da Constituição, está igualmente presente em todos, quer sejam negros ou brancos, ricos ou pobres, pessoas com ou sem deficiência, é necessário e recorrente entre os teóricos. Rocha (2004, p. 13), por exemplo, complementa afirmando: 
Gente é tudo igual. Tudo igual. Mesmo tendo cada um a sua diferença. Gente não muda. Muda o invólucro. O miolo, igual. Gente quer ser feliz, tem medos, esperanças e esperas. Que cada qual vive a seu modo. Lida com as agonias de um jeito único, só seu. Mas o sofrimento é sofrido igual. A alegria, sente-se igual.

Tal reconhecimento da dignidade que há nas pessoas, também nas pessoas com deficiência, é um reconhecimento de suas limitações diversas e de suas múltiplas possibilidades.

Nesse sentido, a Constituição da República Federativa do Brasil, de 5 de outubro de 1988, na Seção IV, do Cap. II, Título VIII, Da Ordem Social, em que trata da problemática jurídica da assistência social, não apresenta as pessoas com deficiência como um grupo naturalmente marginalizado por diversas doenças e que, por isso mesmo, deveria ser um grupo submetido a imposições assistencialistas ou meramente caritativas. A Constituição (art. 203, IV), ao contrário, garante que a assistência social dada aos brasileiros com alguma deficiência tem por objetivo "[...] a promoção de sua integração à vida comunitária". Sendo assim, de modo algum tal dispositivo jurídico deve ser interpretado como um tipo de socorro segregador que, em vez de fortalecer o reconhecimento da humanidade das pessoas com deficiência e o seu direito à inclusão social, reforçaria ainda mais o pesado preconceito histórico que é imposto sobre os seus ombros.

Ao analisar a proteção constitucional das pessoas com deficiência no Brasil e o direito à inclusão social, Araujo $(2014$, p. 9) também disserta sobre o artigo 203, afirmando:

O tema da deficiência vem assegurado quando o direito à habilitação e reabilitação na vida social vem garantido como parte da Assistência Social, no artigo 203. [...]. Não bastasse o princípio do direito à inclusão, constante do artigo terceiro, da ideia de que todos têm direito à habilitação ou reabilitação (artigo 203, inciso IV), há presença forte da igualdade formal. Ou seja, ninguém poderá ser discriminado em virtude de sua deficiência. Não haveria necessidade de tal comando, pois a regra da igualdade já está presente no "caput" do artigo quin- 
to. De toda forma, entendeu o constituinte de proteger específica e expressamente esse grupo vulnerável, mesmo já tendo a igualdade sido garantida e explicitada em outro dispositivo.

O texto constitucional ressalta, por intencionalidade dos legisladores brasileiros, a citação direta das pessoas com deficiência como grupo expressa e formalmente igual em direitos aos demais grupos sociais, estes formados por pessoas consideradas sem deficiência. Tal ênfase do texto legal, por isso, não permite dúvidas de que o conceito de pessoa com deficiência, já no ano 1988, trata-se de um conceito de reconhecimento da dignidade pessoal, do direito à inclusão e da rejeição a qualquer forma de discriminação.

Essa ênfase na afirmação da igualdade e da inclusão, não bastando o reiterado já presente no texto constitucional, ressurge ainda sob uma nova redação no artigo $1^{\circ}$, do Estatuto da Pessoa com Deficiência, de 2015, que ao delimitar o destino desta lei - "assegurar e promover, em condições de igualdade" os direitos das pessoas com deficiência -, reforça também, textualmente, a autonomia das pessoas com deficiência e a sua necessidade de mais "inclusão social e cidadania".

A noção de igualdade entre pessoas com e sem deficiência somada à declaração de autonomia e inclusão contribuem para uma conceituação menos individualizadora e mais socioambiental de pessoa com deficiência.

Segundo Omote (1994, p. 129), desde o final da década de 1950, os estudiosos têm refletido a partir de novos paradigmas acerca das pessoas com deficiência e, por isso, têm ampliado a sua pesquisa, saindo da delimitação fechada apenas do estudo do indivíduo e passando a observar também as questões psicossociais e as relações interpessoais. A partir desses novos estudos, então, a concepção social de pessoa com deficiência passou a dialogar intrinsecamente com o princípio jurídico da igualdade, além de reforçar o dever do Estado, da família e da sociedade de modo geral de atenuar as barreiras sociais que afligem as pessoas com deficiência e dificultam o seu exercício cidadão e o reconhecimento de sua dignidade como pessoa humana. 
Não por acaso, já no primeiro tópico do preâmbulo da Convenção sobre os Direitos das Pessoas com Deficiência, da ONU (2007), está disposto que:

Relembrando os princípios consagrados na Carta das Nações Unidas, que reconhecem a dignidade e o valor inerentes e os direitos iguais e inalienáveis de todos os membros da família humana como o fundamento da liberdade, da justiça e da paz no mundo [...].

Ao valer-se da Carta de São Francisco, de 26 de junho de 1945, o documento sobre os direitos das pessoas com deficiência reconhece a inclusão e a acessibilidade como uma questão essencial de direitos humanos: "Todo ser humano tem direito a um padrão de vida capaz de assegurar-lhe [...] cuidados médicos e os serviços sociais indispensáveis, e direito à segurança em caso de desemprego, doença, invalidez [...]", essas são palavras consagradas pela Declaração Universal dos Direitos Humanos (DUDH), artigo 25, de 10 de dezembro de 1948.

Por isso, é pelo reconhecimento de sua dignidade humana, de sua igualdade diante das demais pessoas, de sua necessidade de atenção social em conformidade com suas limitações, que a pessoa com deficiência, especialmente a partir do século XX e das instituições jurídicas progressistas e democráticas dessa época, passa a ser conceituada de acordo com a sua autonomia e a sua cidadania. Junto a isso, a sociedade como um todo, em decorrência do princípio da fraternidade e dos fundamentos que legitimam a instituição dos Estados Democráticos de Direito, passa então a ser responsabilizada pela promoção dos direitos, pela ampliação das práticas inclusivas e pela superação das suas próprias deficiências e injustiças.

Na procura por responder a esse projeto de sociedade humanista, fraterna e democrática é que a Constituição Federal do Brasil (1988) erigiu dispositivos garantidores como os Direitos Sociais, do artigo $7^{\circ}$, XXXI, que impõe, por exemplo, a "proibição de qualquer discriminação no tocante a salário e critérios de admissão do trabalhador portador de deficiência". 
Dialogando com essa inscrição constitucional, o Estatuto da Pessoa com Deficiência (2015) - respaldado pela Lei Orgânica da Assistência Social, Lei n. 8.742, de 7 de dezembro de 1993 - garante em seu artigo 40 que "É assegurado à pessoa com deficiência que não possua meios para prover sua subsistência, nem de tê-la provida por sua família, o benefício mensal de 1 (um) salário-mínimo [...]".

Ou seja, não apenas a igualdade formal - explícita no caput do artigo $5^{\circ}$ da Constituição Federal do Brasil: -Todos são iguais perante a lei $[\ldots .$. " -, mas também a igualdade material diz respeito à noção contemporânea que se tem de pessoa com deficiência e de sociedade democrática.

Por isso, no artigo $3^{\circ}$, da Constituição Federal do Brasil, afirma-se como sendo objetivo fundamental do Estado brasileiro "erradicar a pobreza e a marginalização".

Nesse sentido é que Segalla \& Araujo (2012, p. 148) dizem: “O princípio da igualdade material, portanto, foi concretizado por tal providência. Já havia instrumentos dessa igualdade material assegurados no texto da Constituição de 1988. Podemos mencionar o salário mínimo existencial", do artigo 203, como um exemplo. Isso, pois, obviamente não bastaria escrever e declarar que as pessoas com deficiência têm direito, necessidade e capacidade de inclusão social plena se, na vida prática, tais pessoas continuassem economicamente desassistidas e marginalizadas. O processo de inclusão, por isso, depende tanto de um discurso humanista garantidor quanto de uma intervenção empírica salarial para as pessoas com deficiência que sejam extremamente pobres.

Araujo (2011, p. 8) indica que o combate à pobreza não apenas serve para a assistência de pessoas com deficiência, mas também para a prevenção de doenças que podem aumentar significativamente o grupo dessas pessoas:

Entre nós [no Brasil], o número elevado de pessoas com deficiência não tem a mesma causa dos países da Europa e dos Estados Unidos. Nosso índice assustador se deve aos acidentes de trânsito, à carência alimentar e à falta de condições de higiene. 
Ou seja, enquanto a Europa, do século XX, viu o número de pessoas com deficiência subir por causa das guerras mundiais, já no Brasil, ainda nos dias de hoje, o amplo grupo de pessoas com deficiência se deve, também, à alta desigualdade material existente, que acarreta diversos prejuízos na saúde pública brasileira.

Por isso, a reflexão atual acerca das pessoas com deficiência não apenas aponta para as injustiças e deficiências da própria sociedade quando da assistência devida e não cumprida, mas aponta ainda para essa sociedade brasileira como sendo a própria causa de parte dos casos de pessoas com deficiência.

\section{Pessoa com deficiênCIA Como CidAdão PRIORITÁrio}

Conscientes disso, os legisladores brasileiros, após amplo debate com a sociedade civil organizada, documentaram no texto oficial do Estatuto da Pessoa com Deficiência (2015), artigo $8^{\circ}$, o conceito de Estado e sociedade provedores junto ao conceito jurídico de pessoa com deficiência como cidadão prioritário quando da garantia e da efetivação dos seus direitos:

É dever do Estado, da sociedade e da família assegurar à pessoa com deficiência, com prioridade, a efetivação dos direitos referentes à vida, à saúde, à sexualidade, à paternidade e à maternidade, à alimentação, à habitação, à educação, à profissionalização, ao trabalho, à previdência social, à habilitação e à reabilitação, ao transporte, à acessibilidade, à cultura, ao desporto, ao turismo, ao lazer, à informação, à comunicação, aos avanços científicos e tecnológicos, à dignidade, ao respeito, à liberdade, à convivência familiar e comunitária, entre outros decorrentes da Constituição Federal [...] e de outras normas que garantam seu bem-estar pessoal, social e econômico.

A prioridade garantida às pessoas com deficiência não contradiz o princípio humanista e constitucional da igualdade, mas pretende exata- 
mente criar meios para a sua concretização dando "tratamento igualitário aos iguais e tratamento diferenciado aos diferentes", conforme resume Napolitano (2010, p. 100). Isto é, para promoção da justiça social e da inclusão, a sociedade democrática deve atender a cada um conforme as suas necessidades, a fim de que, então, todas as pessoas tenham a sua dignidade igualmente respeitada e os seus direitos fundamentais igualmente efetivados. A isonomia, enfim, se mantém ainda como pilar de sustentação do Estado Democrático de Direito, conforme define Barreiros D'Oliveira (2012, p. 01), mesmo com o atendimento social prioritário para as pessoas com deficiência.

A Constituição Federal do Brasil (1988) tem como um de seus valores substanciais a proteção e a integração das pessoas com deficiência e, por isso, o texto constitucional garante diversas regras protetivas específicas para essas pessoas. (NAPOLITANO, 2010, p. 97).

Napolitano (2010) salienta que o direito à igualdade é o que dá fundamento institucional para a proteção e a integração das pessoas com deficiência. Tal igualdade, enquanto princípio, tem dupla finalidade: a) dar parâmetros para quem cria as leis; b) dar parâmetros para quem aplica as leis. Ou seja, uma vez que o princípio da igualdade é o que deve nortear desde a criação até a aplicação das leis, então lei alguma pode ser nascedouro de privilégio ou mesmo de perseguição. Ao contrário, a noção de sociedade igualitária e democrática deve regular as relações e implantar um tratamento igual para todas as pessoas, o que inclui as pessoas com deficiência.

Napolitano (2010), no entanto, reforça que a impossibilidade de se criar, a partir da base constitucional, privilégios ou perseguições não devem ser interpretados como impedimento formal para o tratamento jurídico-social que atenda aos cidadãos em conformidade com as suas necessidades particulares. Reforçando que tal atendimento, conforme as necessidades de cada pessoa, da pessoa com deficiência, por exemplo, deve cumprir os requisitos básicos para que não viole o princípio da igualdade e, de modo geral, o sistema jurídico: 
Parece ambígua a afirmação de que é proibido, mediante lei, criar privilégios e, ao mesmo tempo, afirma-se que a lei pode tratar diferentemente determinadas situações jurídicas. Sem dúvida, o princípio da igualdade impede o tratamento diferenciado às pessoas [...]. (NAPOLITANO, 2010, p. 98-99).

Ou seja, o paradoxo aqui é apenas aparente. Pois, objetivamente, tanto não se deve criar privilégios dentre os cidadãos quanto não se deve omitir a atenção jurídica prioritária aos cidadãos mais necessitados.

Diante de tal constatação, Napolitano usa os três requisitos básicos organizados por Bandeira de Mello (1999, p. 12) para justificar por que meios a lei, que tem como uma de suas funções principais exatamente dispensar tratamentos desiguais quando necessário, deve ser aplicada de modo diferenciado e, ainda assim, justo:

Para se admitir o tratamento desigual, alguns requisitos devem ser observados [...]: 1) o elemento tomado como fator de desigualdade; 2) a correlação lógica abstrata entre o fator elevado a critério de discriminação e o tratamento diferenciado estabelecido pelo ordenamento jurídico; 3) a correspondência dessa correlação lógica com os valores estabelecidos no ordenamento jurídico constitucional.

No caso específico das pessoas com deficiência, o primeiro requisito básico pode ser respondido como sendo a própria deficiência, uma deficiência intelectual grave, por exemplo, o elemento gerador da desigualdade; o segundo requisito pode ser respondido evidenciando a relação entre essa deficiência constatada na pessoa e a previsão legal, por exemplo, de que cabe ao Estado oferecer educação especial gratuita à pessoa; e o terceiro requisito pode ser respondido confirmando a coerência entre a assistência social dada de modo especial a essa pessoa com deficiência intelectual grave e o valor substancial de proteção e de integração da pessoa com deficiência, por exemplo, explícito no texto constitucional. 
Sendo assim, os três requisitos devem ser observados de modo cumulativo para que a regra jurídica diferenciadora não possa ser considerada como não isonômica, ou seja, como desigualmente injusta e, por isso, inconstitucional.

Para exemplificar, Napolitano cita o próprio Artigo $5^{\circ}$ da Constituição Federal do Brasil, que ao mesmo tempo em que diz que todos são iguais perante a lei também estipula algumas regras que almejam diferenciar, proteger e incluir as pessoas com deficiência sem, por isso, que o Artigo $5^{\circ}$ deixe de ter uma coerência interna e esteja, todo ele, pautado pelo princípio da igualdade. A igualdade respeitada como princípio e alcançada por meio de práticas diferenciadas não se aplica apenas na inclusão de pessoas com deficiência, mas também para as mulheres, por exemplo, quando recebem tratamento juridicamente diferenciado; também as crianças e os idosos, os negros, os indígenas, os extremamente pobres etc.

\section{História, Direitos Humanos e políticas inclusivas}

Santos \& Oliveira (2011, p. 434), ao dissertarem sobre a universalidade dos direitos humanos e os direitos da pessoa com deficiência na Constituição Federal do Brasil (1988), afirmam que, apesar da grande evidência dada atualmente a esse debate acerca da inclusão social, já desde a época da Revolução Francesa (1789), a humanidade havia despertado para a reflexão a respeito das necessidades de cada pessoa, o que inclui as pessoas com deficiência. Na Europa do século XVIII, inspirados pelos ideais revolucionários de Jean-Jacques Rousseau, os franceses marcaram a História ao promoverem a bandeira "Liberté, Egalité, Fraternité" - Liberdade, Igualdade, Fraternidade -, e as consequências desse fato e desse discurso repercutem até hoje.

Por exemplo, após o fim da Segunda Guerra Mundial (1939-1945), o princípio da fraternidade voltou ao centro do debate na comunidade internacional. Por isso, liderados pela União das Repúblicas Socialistas Soviéticas (URSS) e pelos Estados Unidos da América (EUA), os dirigentes das nações que emergiram no pós-guerra estabeleceram, durante 
a Conferência de Yalta, na Inglaterra (1945), o alicerce para um novo momento histórico, sob o ideal da união e da paz entre todos. Como fruto desse projeto e alinhados aos princípios universais da liberdade, da igualdade e da fraternidade, criou-se a Organização das Nações Unidas (ONU):

Esse movimento de universalidade do gênero humano atingiu as minorias, trazendo para a ONU a discussão da diversidade. Assim, nesse processo de reconhecimento do homem, a pessoa com necessidades especiais também passou a ser foco de discussão através de outras organizações, especialmente: ENABLE - Organização das Nações Unidas para Pessoas com Deficiência; UNESCO - Organização das Nações Unidas para a Educação, Ciência e Cultura; UNICEF - Fundo das Nações Unidas para a Infância; OMS - Organização Mundial da Saúde. Essas organizações contribuíram para a criação de diversos documentos com o intuito de promover condições para que as pessoas com necessidades especiais pudessem viver dignamente e exercer a cidadania. (SANTOS \& OLIVEIRA, 2011, p. 434).

A discussão acerca do gênero humano e sua dignidade tem grande impulso histórico a partir da instituição da ONU, de modo especial com a Declaração Universal dos Direitos Humanos, de 1948.

Então, em 1976, como consequência dessa reflexão humanista que vinha ocorrendo no mundo, foi comemorado o Ano Internacional das Pessoas com Deficiência, com o tema "A participação plena e a igualdade", evento que contribuiu para a conscientização dos diversos países-membros da ONU sobre as necessidades e as potencialidades das pessoas com deficiência.

Essa mobilização possibilitou retirar grande ensinamento: a imagem da pessoa com deficiência depende das atitudes sociais, que, por sua vez, são o principal obstáculo à realização dos objetivos da participação plena e da igualdade. (SANTOS \& OLIVEIRA, 2011, p. 434). 
Ou seja, o conceito de pessoa com deficiência a partir de uma crítica às limitações sociais é confirmado também nesse caso e o Brasil, por ser signatário desse movimento mundial, obriga-se à garantia de tais direitos fundamentais. Santos \& Oliveira (2011, p. 435), trabalhando segundo o teórico Paulo Bonavides, caracterizam o Estado brasileiro como um Estado social e que, por isso, deve ser um Estado produtor de igualdade fatídica, isto é, além de o Brasil precisar evitar ser um obstáculo para as pessoas com deficiência, cabe ainda a ele obrigar prestações positivas, quando necessário, provendo todos os meios úteis para a concretização dos comandos normativos de isonomia em benefício das pessoas com deficiência.

Santos \& Oliveira ressaltam, porém, que apesar de o texto constitucional brasileiro ter a preocupação de promover a igualdade e de citar diretamente as pessoas com deficiência, isso não significa que, de fato, as políticas públicas implantadas pelo Brasil já tenham chegado a todas as pessoas que necessitam de atenção especial. Isto é, o conceito jurídico de pessoa com deficiência já está posto e a crítica às barreiras sociais é feita recorrentemente, no entanto, a prática política ainda é insatisfatória e pouco abrangente.

Como exemplo, é possível ver o caso específico da educação inclusiva e especial. Tal educação já é um direito consagrado, mas efetivamente ainda não universalizado.

O artigo 206 da Constituição Federal do Brasil garante a igualdade de condições para o acesso e permanência na escola e o artigo 208 determina que é dever do Estado oferecer atendimento educacional especializado, preferencialmente nas escolas regulares, para os alunos com deficiência.

Refletindo o texto constitucional, a Lei de Diretrizes e Bases da Educação Nacional (LDB), Lei n. 9394/96, detalha o suporte legal para a inclusão do aluno com deficiência nas unidades escolares e determina que as redes de ensino garantam aos alunos com necessidades especiais o currículo, o método, os recursos e a organização específica, em conformidade com as suas características. A LDB ainda assegura aos alunos que não conseguem concluir o ensino fundamental, em razão de 
alguma deficiência, a possibilidade de um término específico em consonância com a sua realidade e limitação, como também cita o direito de aceleração dos estudos e do programa escolar para os alunos que apresentarem superdotação.

E há ainda o Decreto n. 3.298/99, que trata da política nacional de integração da pessoa com deficiência e também aborda, diretamente, o tema da educação definindo educação especial como sendo uma modalidade transversal, que deve se dar em todos os níveis e em todas as modalidades de ensino, com ênfase de ser complemento da educação regular, ou seja, a educação especial não deve ser mais uma forma de marginalização, mas sim um auxílio para a educação inclusiva.

Para apresentar a efetivação dessas leis e desse novo conceito de pessoa com deficiência como capaz de participação e dona do direito à participação, Santos \& Oliveira (2011, p. 436) apresentam dados concretos:

Como resultado dessas políticas, as estatísticas mostram que, no período de 1998 a 2006, conforme dados do Censo Escolar desse período, com relação à educação especial, ocorreu uma evolução nas matrículas, de 337.326 em 1998 para 700.624 em 2006, expressando um crescimento de $107 \%$. No que se refere ao ingresso em classes comuns do ensino regular, verifica-se um crescimento de $640 \%$, passando de 43.923 alunos em 1998 para 325.316 em 2006.

Fora o avanço significativo nas matrículas, também é desse período a criação do programa nacional de Educação, Tecnologia e Profissionalização para Pessoas com Necessidades Educacionais Especiais (TEC-NEP). Esse programa é uma proposta que tenta a realização da relação que há entre a Constituição Federal do Brasil, que no artigo 205 garante a qualificação para o trabalho, e a LDB/1996, que no artigo $1^{\circ}$, parágrafo segundo, afirma que a educação deve estar vinculada, além da prática social de modo amplo, diretamente ao mundo do trabalho.

Para atender a essa determinação legal e sob o conceito jurídico inclusivo de pessoa com deficiência é que a Secretaria de Educação 
Especial (SEESP) e a Secretaria de Educação Tecnológica (SETEC) organizaram, na cidade de Brasília/DF, no ano 2000, a oficina de trabalho intitulada "PNE - Uma questão de inclusão", que teve ampla participação de representantes de Estados brasileiros e de instituições que trabalham com alunos com deficiência, para debater, conscientizar e mobilizar a sociedade brasileira na direção da acessibilidade de pessoa com necessidades educacionais especiais nos projetos político-pedagógicos.

Como fruto dessa unidade, o programa TEC-NEP tem trabalhado em busca do seu objetivo primeiro: construir, Brasil afora, centros de referência de educação profissional para pessoa com deficiência. E essa reflexão acerca do preparo para o mundo do trabalho somada aos conceitos de Sassaki (2003) levaram Santos \& Oliveira a salientarem o progresso dentro do conceito de pessoa com deficiência.

As discussões referentes ao preparo profissional e integração ao mundo do trabalho das pessoas com necessidades especiais verificam que para ocorrer o princípio da igualdade é necessário mudar o paradigma que atualmente norteia a relação da pessoa com deficiência na sociedade, o paradigma da integração, pois para se atingir a desejada igualdade esse ainda não é o paradigma ideal. (SANTOS \& OLIVEIRA, 2011, p. 437).

\section{LINGUAGEM INCLUSIVA E DIGNIDADE HUMANA}

Sassaki (2003), que está na base da posição de Santos \& Oliveira, faz um levantamento terminológico e histórico que pode ser resumido conforme exposto a seguir: 


\begin{tabular}{|c|c|c|}
\hline ÉPOCA & TERMOS E SENTIDOS & VALORAÇÃO \\
\hline $\begin{array}{l}\text { Desde o começo da } \\
\text { história escrita, du- } \\
\text { rante séculos. } \\
\text { Romances, nomes } \\
\text { de instituições, } \\
\text { leis, mídia e outros } \\
\text { meios menciona- } \\
\text { vam "os inválidos". } \\
\text { Exemplo: "A reabi- } \\
\text { litação profissional } \\
\text { visa a proporcionar } \\
\text { aos beneficiários in- } \\
\text { válidos...". (Decreto } \\
\text { Federal no } 60.501 \text {, } \\
\text { de } 14 / 3 / 67, \text { dando } \\
\text { nova redação ao } \\
\text { Decreto } \text { n }^{\circ} 48.959- \\
\text { A, de } 19 / 9 / 60) .\end{array}$ & $\begin{array}{l}\text { "Os inválidos". O termo } \\
\text { significava, "indivíduos } \\
\text { sem valor". Em pleno sé- } \\
\text { culo XX, ainda se utilizava } \\
\text { este termo, embora sem } \\
\text { necessariamente um senti- } \\
\text { do pejorativo. } \\
\text { Outro exemplo: "Inválidos } \\
\text { insatisfeitos com lei relati- } \\
\text { va aos ambulantes" (Diário } \\
\text { Popular, 21/4/76). }\end{array}$ & $\begin{array}{l}\text { Aquele que tinha deficiência } \\
\text { era tido como socialmente } \\
\text { inútil, um peso morto para } \\
\text { a sociedade, um fardo para } \\
\text { a família, alguém sem valor } \\
\text { profissional. } \\
\text { Outros exemplos: "Servidor } \\
\text { inválido pode voltar" (Folha } \\
\text { de S. Paulo, 20/7/82). "Os } \\
\text { cegos e o inválido" (IstoÉ, } \\
7 / 7 / 99 \text { ). }\end{array}$ \\
\hline $\begin{array}{l}\text { Século } 20 \text { até } \pm \\
1960 . \text { "Derivativo } \\
\text { para incapacitados" } \\
\text { (Shopping News, } \\
\text { Coluna Radioama- } \\
\text { dorismo, 1973). } \\
\text { "Escolas para } \\
\text { crianças incapazes" } \\
\text { (Shopping News, } \\
\text { 13/12/64). } \\
\text { Após I e II Guer- } \\
\text { ras Mundiais, a mí- } \\
\text { dia usava termo } \\
\text { assim: "A guerra } \\
\text { produziu incapa- } \\
\text { citados", "Os in- } \\
\text { capacitados agora } \\
\text { exigem reabilitação } \\
\text { física". }\end{array}$ & $\begin{array}{l}\text { "Os incapacitados". O ter- } \\
\text { mo significava, de início, } \\
\text { "indivíduos sem capacida- } \\
\text { de" e, mais tarde, evoluiu } \\
\text { e passou a significar "in- } \\
\text { divíduos com capacidade } \\
\text { residual". Durante várias } \\
\text { décadas, era comum o uso } \\
\text { deste termo para designar } \\
\text { pessoas com deficiência } \\
\text { de qualquer idade. Uma } \\
\text { variação foi o termo "os } \\
\text { incapazes", que significa- } \\
\text { va "indivíduos que não são } \\
\text { capazes" de fazer algumas } \\
\text { coisas por causa da defici- } \\
\text { ência que têm. }\end{array}$ & $\begin{array}{l}\text { Foi um avanço a sociedade } \\
\text { reconhecer que a pessoa com } \\
\text { deficiência poderia ter capa- } \\
\text { cidade residual, mesmo que } \\
\text { reduzida. } \\
\text { Mas ao mesmo tempo, con- } \\
\text { siderava-se que a deficiência, } \\
\text { qualquer que fosse o tipo, } \\
\text { eliminava ou reduzia a capa- } \\
\text { cidade da pessoa em todos os } \\
\text { aspectos: físico, psicológico, } \\
\text { social, profissional etc. }\end{array}$ \\
\hline
\end{tabular}




\begin{tabular}{|c|c|c|}
\hline ÉPOCA & TERMOS E SENTIDOS & VALORAÇÃO \\
\hline $\begin{array}{l}\text { De } \pm 1960 \text { até } \pm \\
1980 . \\
\text { "Crianças defeitu- } \\
\text { osas na Grã-Breta- } \\
\text { nha têm educação } \\
\text { especial" (Shopping } \\
\text { News, 31/8/65). } \\
\text { No final da déca- } \\
\text { da de 50, foi fun- } \\
\text { dada a Associação } \\
\text { de Assistência à } \\
\text { Criança Defeituo- } \\
\text { sa-AACD (hoje de- } \\
\text { nominada Associa- } \\
\text { ção de Assistência à } \\
\text { Criança Deficiente). } \\
\text { Na década de 50 } \\
\text { surgiram as pri- } \\
\text { meiras unidades da } \\
\text { Associação de Pais e } \\
\text { Amigos dos Excep- } \\
\text { cionais- APAE. }\end{array}$ & $\begin{array}{l}\text { "Os defeituosos". O ter- } \\
\text { mo significava "indiví- } \\
\text { duos com deformidade" } \\
\text { (principalmente física). } \\
\text { "Os deficientes". Este ter- } \\
\text { mo significava "indivíduos } \\
\text { com deficiência" física, } \\
\text { intelectual, auditiva, visual } \\
\text { ou múltipla, que os levava } \\
\text { a executar as funções bási- } \\
\text { cas de vida (andar, sentar- } \\
\text {-se, correr, escrever, tomar } \\
\text { banho etc.) de uma forma } \\
\text { diferente daquela como as } \\
\text { pessoas sem deficiência } \\
\text { faziam. E isto começou a } \\
\text { ser aceito pela sociedade. } \\
\text { "Os excepcionais". O ter- } \\
\text { mo significava "indivíduos } \\
\text { com deficiência intelectu- } \\
\text { al". }\end{array}$ & $\begin{array}{l}\text { A sociedade passou a uti- } \\
\text { lizar estes três termos, que } \\
\text { focalizam as deficiências } \\
\text { em si sem reforçarem o } \\
\text { que as pessoas não conse- } \\
\text { guiam fazer como a maioria. } \\
\text { Simultaneamente, difundia- } \\
\text {-se o movimento em defesa } \\
\text { dos direitos das pessoas su- } \\
\text { perdotadas (expressão subs- } \\
\text { tituída por "pessoas com } \\
\text { altas habilidades" ou "pes- } \\
\text { soas com indícios de altas } \\
\text { habilidades"). O movimen- } \\
\text { to mostrou que o termo "os } \\
\text { excepcionais" não poderia } \\
\text { referir-se exclusivamente aos } \\
\text { que tinham deficiência inte- } \\
\text { lectual, pois as pessoas com } \\
\text { superdotação também são } \\
\text { excepcionais por estarem na } \\
\text { outra ponta da curva da inte- } \\
\text { ligência humana. }\end{array}$ \\
\hline $\begin{array}{l}\text { De } 1981 \text { até } \pm 1987 . \\
\text { Por pressão das or- } \\
\text { ganizações de pesso- } \\
\text { as com deficiência, } \\
\text { a ONU deu o nome } \\
\text { de "Ano Internacio- } \\
\text { nal das Pessoas De- } \\
\text { ficientes" ao ano de } \\
1981 \text {. } \\
\text { E o mundo achou di- } \\
\text { fícil começar a dizer } \\
\text { ou escrever "pesso- } \\
\text { as deficientes". O } \\
\text { impacto desta nova } \\
\text { terminologia foi } \\
\text { profundo e ajudou a } \\
\text { melhorar a imagem } \\
\text { dessas pessoas. }\end{array}$ & $\begin{array}{l}\text { "Pessoas deficientes". } \\
\text { Pela primeira vez em todo } \\
\text { o mundo, o substantivo } \\
\text { "deficientes" passou a ser } \\
\text { utilizado como adjetivo, } \\
\text { sendo-lhe acrescentado o } \\
\text { substantivo "pessoas". } \\
\text { A partir de 1981, "indi- } \\
\text { víduos" passou a não ser } \\
\text { mais utilizado. }\end{array}$ & $\begin{array}{l}\text { Foi atribuído o valor "pes- } \\
\text { soas" àqueles que tinham } \\
\text { deficiência, igualando-os } \\
\text { em direitos e dignidade aos } \\
\text { membros de qualquer socie- } \\
\text { dade ou país. } \\
\text { A Organização Mundial de } \\
\text { Saúde (OMS) lançou em } \\
1980 \text { a Classificação Interna- } \\
\text { cional de Impedimentos, De- } \\
\text { ficiências e Incapacidades, } \\
\text { mostrando que estas três di- } \\
\text { mensões existem simultane- } \\
\text { amente em cada pessoa com } \\
\text { deficiência. }\end{array}$ \\
\hline
\end{tabular}




\begin{abstract}
ÉPOCA
De \pm 1988 até \pm 1993 . Alguns líderes de organizações de pessoas com deficiência contestaram o termo "pessoa deficiente" alegando que ele sinaliza que a pessoa inteira é deficiente, 0 que era inaceitável para eles.
\end{abstract}

\section{Anos 1990.}

$O$ art. $5^{\circ}$ da Resolução CNE/CEB n ${ }^{\circ}$ 2, de 11/9/01, explica que as necessidades especiais decorrem de situações envolvendo tanto dificuldades vinculadas a deficiências quanto dificuldades não-vinculadas a uma causa orgânica. Ainda anos 1990. Surgiram expressões como "crianças especiais", "alunos especiais", "pacientes especiais" e assim por diante, numa tentativa de amenizar a contundência da palavra "deficientes". Ainda anos 1990.

A Declaração de Salamanca preconizou a educação inclusiva para todos, tenham ou não uma deficiência.

\section{TERMOS E SENTIDOS \\ "Pessoas portadoras de} deficiência". Termos que foi proposto para substituir o termo "pessoas deficientes".

Mas logo reduziram estes termos para apenas "portadores de deficiência".

"Pessoas com necessidades especiais". O termo surgiu primeiramente para substituir "deficiência" por "necessidades especiais", daí a expressão "portadores de necessidades especiais". Depois, esse termo passou a ter significado próprio sem substituir o nome "pessoas com deficiência".

"Pessoas especiais". O termo apareceu como uma forma reduzida da expressão "pessoas com necessidades especiais", constituindo um eufemismo dificilmente aceitável para designar um segmento populacional.

"Pessoas com deficiência" e pessoas sem deficiência, quando tiverem necessidades educacionais especiais e se encontrarem segregadas, têm o direito de fazer parte das escolas inclusivas dentro de uma sociedade inclusiva e democrática.

\section{VALORAÇÃO}

O "portar uma deficiência" passou a ser um valor relativo à pessoa. A deficiência passou a ser um aspecto da pessoa.

O termo foi adotado nas Constituições Federal e Estaduais e em todas as leis e políticas pertinentes ao campo das deficiências até então. Conselhos, coordenadorias e associações passaram a incluir o termo em seus nomes oficiais.

De início, "necessidades especiais" representava apenas um novo termo. Depois, com a vigência da Resolução $n^{\circ}$ 2, "necessidades especiais" passou a ser um valor agregado tanto à pessoa com deficiência quanto a outras pessoas, com garantia de direitos.

O adjetivo "especiais" permanece como uma simples palavra, sem agregar valor diferenciado às pessoas com deficiência. O "especial" não é qualificativo exclusivo das pessoas que têm deficiência, pois ele se aplica a qualquer pessoa.

$\mathrm{O}$ valor agregado às pessoas é o de elas fazerem parte do grande segmento dos excluídos, que exigem sua inclusão em todos os aspectos da vida da sociedade. Trata-se do início do discurso de "empoderamento" de minorias sociais. 


\begin{tabular}{|c|c|c|}
\hline ÉPOCA & TERMOS E SENTIDOS & VALORAÇÃO \\
\hline $\begin{array}{l}\text { Em maio de } 2002 . \\
\text { Frei Betto escreveu } \\
\text { no jornal O Estado } \\
\text { de S.Paulo um artigo } \\
\text { em que propõe o ter- } \\
\text { mo "portadores de } \\
\text { direitos especiais" } \\
\text { e a sigla PODE. } \\
\text { Alega o proponente } \\
\text { que o substantivo } \\
\text { "deficientes" e o ad- } \\
\text { jetivo "deficientes" } \\
\text { encerram s signifi- } \\
\text { cado de falha ou im- } \\
\text { perfeição enquanto } \\
\text { que a sigla PODE } \\
\text { exprime capacidade. } \\
\text { O artigo, ou parte } \\
\text { dele, foi reproduzido } \\
\text { em revistas especia- } \\
\text { lizadas em assuntos } \\
\text { de deficiência. }\end{array}$ & $\begin{array}{l}\text { "Portadores de direitos es- } \\
\text { peciais". O termo e a sigla } \\
\text { apresentam problemas que } \\
\text { inviabilizam a sua adoção } \\
\text { em substituição a qualquer } \\
\text { outro termo para designar } \\
\text { pessoas que têm deficiên- } \\
\text { cia. O termo "portadores" } \\
\text { já vem sendo questionado } \\
\text { por sua alusão a "carrega- } \\
\text { dores", pessoas que "por- } \\
\text { tam" (levam) uma defici- } \\
\text { ência. O termo "direitos } \\
\text { especiais" é contraditório } \\
\text { porque as pessoas com } \\
\text { deficiência exigem equipa- } \\
\text { ração de direitos e não di- } \\
\text { reitos especiais. E mesmo } \\
\text { que defendessem direitos } \\
\text { especiais, o nome "porta- } \\
\text { dores de direitos especiais" } \\
\text { não poderia ser exclusivo } \\
\text { das pessoas com defici- } \\
\text { ência, pois qualquer outro } \\
\text { grupo vulnerável pode rei- } \\
\text { vindicar direitos especiais. }\end{array}$ & $\begin{array}{l}\text { Não há valor a ser agregado } \\
\text { com a adoção deste termo, } \\
\text { por motivos expostos na co- } \\
\text { luna ao lado. } \\
\text { A sigla PODE, apesar de } \\
\text { lembrar "capacidade", apre- } \\
\text { senta problemas de uso: } \\
\text { 1) Imaginem a mídia e ou- } \\
\text { tros autores escrevendo ou } \\
\text { falando assim: "Os Podes de } \\
\text { Osasco terão audiência com } \\
\text { o Prefeito...", "A Pode Ma- } \\
\text { ria de Souza manifestou-se a } \\
\text { favor...", "A sugestão de José } \\
\text { Maurício, que é um Pode, } \\
\text { pode ser aprovada hoje..." } \\
\text { 2) Pelas normas brasileiras } \\
\text { de ortografia, a sigla PODE } \\
\text { precisa ser grafada "Pode". }\end{array}$ \\
\hline $\begin{array}{l}\text { Atualmente. } \\
\text { A década de } 90 \text { e a } \\
\text { primeira década } \\
\text { do Terceiro Milê- } \\
\text { nio estão vivendo } \\
\text { inúmeros eventos } \\
\text { mundiais liderados } \\
\text { por organizações de } \\
\text { pessoas com defici- } \\
\text { ência. }\end{array}$ & $\begin{array}{l}\text { "Pessoas com deficiência" } \\
\text { passa a ser o termo prefe- } \\
\text { rido por um número cada } \\
\text { vez maior de adeptos, boa } \\
\text { parte dos quais é constitu- } \\
\text { ída pelas próprias pessoas } \\
\text { com deficiência que, no } \\
\text { maior evento das organiza- } \\
\text { ções de pessoas com defi- } \\
\text { ciência, realizado no Reci- } \\
\text { fe, em } 2000 \text {, conclamaram } \\
\text { o público a adotar este } \\
\text { termo. Elas esclareceram } \\
\text { que não são "portadoras } \\
\text { de deficiência" e que não } \\
\text { querem ser chamadas com } \\
\text { tal nome. }\end{array}$ & $\begin{array}{l}\text { Os valores agregados às pes- } \\
\text { soas com deficiência são: } \\
\text { 1) o do empoderamento [uso } \\
\text { do poder pessoal para fazer } \\
\text { escolhas, tomar decisões e } \\
\text { assumir o controle da situa- } \\
\text { ção de cada um] e } \\
\text { 2) o da responsabilidade de } \\
\text { contribuir com seus talentos } \\
\text { para mudar a sociedade rumo } \\
\text { à inclusão de todas as pesso- } \\
\text { as, com ou sem deficiência. }\end{array}$ \\
\hline
\end{tabular}

Fonte: Sassaki (2003). 
Esse levantamento feito por Sassaki sustenta parte da discussão de Santos \& Oliveira. Assim, o paradigma da integração, pensado a partir de uma visão individualizadora das deficiências, já não reponde bem à sociedade igualitária e democrática que as leis brasileiras e os direitos humanos impõem. O paradigma da inclusão social ou sociedade inclusiva é um avanço pautado por um conceito mais estrutural e complexo das deficiências.

Ou seja, se por um lado o paradigma da integração consiste na busca por adaptar as pessoas com deficiência aos sistemas sociais comuns e, nos casos em que as pessoas não conseguirem essa adaptação, aos sistemas especiais, por outro lado o paradigma da sociedade inclusiva trabalha pelas mudanças ambientais, institucionais, na tentativa de tornar a vida social, em sentido pleno, acessível para toda a diversidade humana existente, o que inclui as pessoas com deficiência.

A sociedade inclusiva está focada nas necessárias transformações estruturais, nas escolas, nas empresas privadas, na mídia, no trânsito, nos espaços de lazer etc., pois do respeito à dignidade da pessoa humana, princípio máximo dos direitos fundamentais, emerge o respeito à autonomia de cada indivíduo, logo, por coerência a esse princípio, a sociedade inclusiva deve criar políticas públicas visando o aumento da liberdade das pessoas com deficiência, pois aumentar a liberdade é não apenas incluir essas pessoas, mas, essencialmente, é afirmar a sua humanidade.

Santos \& Oliveira continuam, assim, a dissertar acerca da igualdade para as pessoas com deficiência e, por isso, citam a Convenção da Guatemala (1999), internalizada no Brasil pelo Decreto n. 3.956/2001, como um momento de confirmação jurídica de que toda e qualquer discriminação ou marginalização das pessoas com deficiência é, diretamente, uma agressão às liberdades humanas fundamentais.

No Brasil, as organizações voltadas para a busca dos direitos da pessoa com deficiência têm lutado para que o princípio da igualdade seja respeitado. Hoje, a pessoa com deficiência tem adquirido direitos nas mais diversas áreas, desde o direito a acompanhante em hospitais à reserva de assentos para o lazer (SANTOS \& OLIVEIRA, 2011, p. 438). 
Fora a saúde e o lazer, Santos \& Oliveira dão o exemplo da obrigatoriedade que a lei impõe às empresas privadas de contratar e manter em seu quadro de funcionários um mínimo de profissionais com deficiência, aprimorando assim a inclusão no mercado de trabalho enquanto efetiva o princípio da igualdade.

Porém, apesar dessas garantias legais, a violação dos direitos das pessoas com deficiência é evidente na sociedade atual, conforme afirma Gomes da Silva (2012):

Tendo em vista os princípios constitucionais da dignidade da pessoa humana e da igualdade, que muitas vezes são esquecidos ou simplesmente não compreendidas pela sociedade com relação aos portadores de deficiência, se faz necessário um estudo aprofundado, dando-se prioridade à violação de seus direitos, sua inclusão na sociedade e os benefícios por ela trazidos.

Gomes da Silva (2012) complementa a noção jurídica contemporânea de pessoa com deficiência afirmando, incialmente, que é escassa a doutrina que trata diretamente dessa matéria, porém os especialistas Araujo (2003) e Gonçalves (2003) contribuem para lançar bases a essa discussão.

Gonçalves (2003, p. 20) faz um levantamento de nomenclaturas, além das mais conhecidas e recorrentes, também das mais técnicas usadas no meio jurídico internacional. Por exemplo, a teoria tem feito uso de termos como "deficiente", que é o mais usado, "indivíduo com capacidade limitada", "inválido", "pessoa portadora de necessidades especiais", "excepcional", "descapacitado", "impedido", "minorado", "minusválido", e ainda os termos recorrentes entre os juristas ingleses, "disable person", "handicapped person", "unusual person" e "special person".

Gomes da Silva (2012) afirma que algumas dessas expressões querem ressaltar a incapacidade, outras a deficiência em si, outras a pessoa. E tal como é o problema terminológico, assim também é o problema propriamente conceitual: é complexo, cheio de variáveis, submetido a momentos históricos e regiões geográficas diversas. 
Ou seja, cada teórico tem liberdade para usar os termos e trabalhar segundo os conceitos que acredita serem mais adequados ainda que a tendência contemporânea é o uso da expressão "pessoa com deficiência" e o conceito mais equiparável aos princípios da dignidade da pessoa humana e da igualdade é o conceito que descentraliza a deficiência do indivíduo defendendo uma transformação social em prol da inclusão de todos.

Especificamente no caso jurídico brasileiro, Gomes da Silva fala de três momentos dentre os mais recentes. Por exemplo, a Emenda Constitucional n. 1, de 1969, traz a palavra "excepcionais": "educação de excepcionais" (Artigo 175, Parágrafo 4). E a Emenda Constitucional n. 12, de 1978, usa o termo mais comum, "deficiente": "é assegurado aos deficientes a melhoria de sua condição social e econômica" (Artigo Único). Já na Constituição Federal do Brasil (1988), a expressão usada por treze vezes é "portador(a) de deficiência", algumas vezes o texto constitucional apresenta a expressão completa "pessoa portadora de deficiência".

Gomes da Silva (2012) diz que, antes de chegar até a expressão atual "pessoa com deficiência", a reflexão linguística pela busca por diminuição de estigmas e por mais inclusão propôs que em vez de "pessoas portadoras de deficiência", usada na Constituição Federal, fosse empregada a expressão "pessoa portadora de necessidade especiais", que é inspirada nos textos de língua inglesa (LUNARD \& COELHO, 2003, p. 476).

Partindo da observação feita por Araujo (2003), ao refletir sobre a expressão que emprega os termos "pessoa" e "deficiência", Gomes da Silva (2012) diz que essa expressão "[...] traz como núcleo a palavra "pessoa", e o termo "deficiência" figura como um qualificativo, ou seja, valoriza-se a pessoa, e já a qualificação "deficiência" apenas completa a ideia nuclear".

Isto é, objetiva-se dar atenção à dignidade da pessoa humana das pessoas com deficiência e sua igualdade diante dos demais cidadãos, importa então evitar na atualidade termos como "deficiente", "especial", "defeituoso", "aleijado" etc., pois estes podem reforçar o conceito histórico da pessoa com deficiência como sendo menos humana ou 
mesmo desumana e, por isso, naturalmente excluída da normalidade. Ora, o uso da expressão "pessoa com deficiência", por isso, não é uma mera opção estilística ou estética, mas é sinal de uma busca pela linguagem inclusiva e pelo discurso pautado nos princípios humanistas fundamentais.

\section{Indivíduos deficientes ou deficiências sociais?}

Tal reflexão terminológica está intimamente vinculada à reflexão conceitual, por isso é que Gomes da Silva (2012) afirma que "O conceito de "deficiente" na forma esposada pela Constituição Federal, de 1988, não está no indivíduo, mas na sua capacidade de relacionamento social"; tal capacidade não depende, pois, unicamente da pessoa, mas prioritariamente depende do meio, do ambiente, da estrutura em volta da pessoa, esta estrutura que pode ser mais ou menos deficiente no que diz respeito à inclusão democrática de toda diversidade humana que compõe uma sociedade.

Segundo Araujo (2003, p. 26), o que define uma pessoa como pessoa com deficiência não é a ausência de um de seus membros físicos nem, tampouco, uma velocidade de raciocínio diferente ou uma visão ou audição reduzida. O que caracteriza a pessoa com deficiência é a dificuldade de participação plena na sociedade. Ou seja, não é propriamente a ausência de um membro do corpo humano que faz que se defina uma pessoa como pessoa com deficiência e, por isso, com direitos exclusivos. Na verdade, é o grau de dificuldade que uma pessoa tem para interagir com a sociedade que faz dela uma pessoa com ou sem deficiência.

Nessa linha de raciocínio, entende-se o porquê de não se considerar como pessoa com deficiência, e portadora de direitos especiais, as pessoas que tenham limitações leves decorrentes, por exemplo, de doenças ou acidentes que não tenham alterado significativamente o seu potencial de interação social. Ou seja, é diferente o tratamento jurídico dado a uma pessoa com paraplegia e a uma pessoa que não tenha parte de um dos seus dedos. Isto, pois, o que se avalia na conceituação jurídica de pessoa com deficiência prioritariamente são as consequências 
limitadoras decorrentes de uma determinada realidade que acomete a pessoa, se tal realidade não diminui a possibilidade de participação social plena, então ela não justifica uma atenção especial do Estado.

Aqui, novamente, o conceito contemporâneo de pessoa com deficiência está intimamente vinculado à situação social, de modo que o foco da definição não está em uma doença que um indivíduo tenha, mas está no grau de sociabilidade que o meio possibilita a esse indivíduo.

No entanto, Gomes da Silva (2012) ressalta que a análise dessas limitações próprias de cada indivíduo, além da análise das causas da limitação, não são juridicamente simples, pois a Constituição Federal brasileira não disciplina o rol das causas específicas de deficiência e, sendo assim, a jurisprudência e debate público de modo geral têm precisado usar-se de classificações genéricas, como a adotada pela Organização Mundial da Saúde (OMS), que tratam apenas das realidades mais frequentes, como das deficiências mental, motora, auditiva, visual e múltipla.

Gomes da Silva exemplifica essa visão panorâmica das deficiências apresentando dados de 2011, do Ministério da Saúde, com base na OMS:

O dimensionamento da problemática da deficiência no Brasil, tanto em termos qualitativos quanto quantitativos, é muito difícil em razão da inexistência quase total de dados e informações de abrangência nacional, produzidos sistematicamente, que retratem de forma atualizada a realidade do País nesta área. A Organização Mundial de Saúde estima que cerca de $10 \%$ da população de qualquer país em tempo de paz é portadora de algum tipo de deficiência, das quais: $5 \%$ é portadora de deficiência mental; $2 \%$ de deficiência física; $1,5 \%$ de deficiência auditiva; $0,5 \%$ de deficiência visual; e $1 \%$ de deficiência múltipla. Com base nesses percentuais, estima-se que no Brasil existam 16 milhões de pessoas portadoras de deficiência.

Mas, de modo geral, os dados do Censo de 2010, pelo IBGE, apresentam 45,6 milhões de brasileiros que declaram ter algum tipo de deficiência, sendo que as mais comuns são: 18,8\% de deficiência visual, 
$7 \%$ de deficiência motora, $5,1 \%$ auditiva, $1,4 \%$ mental ou intelectual $(\mathrm{O}$ ESTADO DE S.PAULO, 2012).

\section{Considerações Finais}

Enfim, a definição de pessoa com deficiência, para aquisição dos direitos especiais previstos em lei, depende de uma análise específica para aferir o grau de interação social de cada pessoa.

Araujo (2003), por isso, dá exemplos concretos, com os quais pretende-se resumir e concluir a problemática trabalhada neste artigo. Tais exemplos são de realidades que podem diminuir acentuadamente o grau de interação social de uma pessoa com deficiência: os alcoólatras e demais drogados, os superdotados, as pessoas com HIV, com esclerose múltipla, com insuficiência renal crônica etc. Todas essas situações são ao mesmo tempo físicas e sociais e é do estudo dessa dialética, entre a doença e o convívio social, que se pode compreender a necessidade de atenção específica para as pessoas com tais deficiências.

$\mathrm{Na}$ mesma direção de síntese, ao dissertar acerca do Artigo $3^{\circ}$, da Lei n. 7.853, de 1989, que versa sobre a Política Nacional para Integração da Pessoa Portadora de Deficiência, Gomes da Silva (2012) afirma:

Por outro lado, para além dos conceitos e categorias, é importante verificar o grau de deficiência, pois o grupo de pessoas portadoras de deficiência não se caracteriza por qualquer grau de deficiência. Há que se atentar para o grau, que envolve essa dificuldade de integração social. Ressalte-se a importância da "integração social", eis que a proteção constitucional se restringe às pessoas que "apresentam um grau acentuado de dificuldade", cuja verificação só poderá ser feita diante de um caso concreto.

Aprofunda-se, assim, a noção de que não é qualquer limitação decorrente de doença ou acidente que garante a aquisição de direitos especiais e que não é, também, por meio de estatísticas nacionais ou mundiais que se classifica o rol de situações ou grupos a quem o Estado deve atenção diferenciada. 
O movimento jurídico atual vai em direção de atender expressa e unicamente as pessoas com deficiência que apresentam um grau inquestionável de dificuldade de participação social, pois isso justifica as ações afirmativas previstas em lei: cotas trabalhistas em empresas privadas, cotas para acesso ao ensino superior, adaptação física dos espaços para promoção da acessibilidade, salário mínimo para pessoas com deficiência pobres etc., e tais ações só podem qualificadamente ser usufruídas após o estudo de caso de cada indivíduo que autodeclara-se como pessoa com deficiência.

Compreende-se, enfim, a partir dos especialistas consultados e da legislação analisada, que a noção jurídica de pessoa com deficiência, atualmente, tende para uma conceituação socioambiental e não mais segregadora como o foi historicamente.

\section{REFERÊNCIAS}

ARAUJO, L.A.D. Um breve quadro da proteção constitucional das pessoas com deficiência no Brasil. Legislação basta? Uma tentativa de diagnóstico. Revista Inclusiones, Revista de Humanidades e Ciências Sociales. v.1. n.3, p.19-30, 2014.

. A proteção constitucional das pessoas com deficiência. Brasília: Corde, 2011. Disponível em: <http://www.pessoacomdeficiencia.gov.br/app/ sites/default/files/publicacoes/a-protecao-constitucional-das-pessoas-com-deficiencia_0.pdf> Acesso em: 16 jan.2016.

. Pessoa portadora de deficiência: proteção constitucional das pessoas portadoras de deficiência. 3. ed., rev., ampliada e atualizada. Brasília: CORDE, 2003.

BANDEIRA DE MELLO, C.A. Conteúdo jurídico do princípio da igualdade. São Paulo: Malheiros, 1999.

BARREIROS D'OLIVEIRA, M. C. Breve análise do princípio da isonomia. Disponível em: <http://institutoprocessus.com.br/2012/wp-content/uploads/2011/12/3_edicao1.pdf> Acesso em: 20 jan. 2016.

BONAVIDES, P. Curso de Direito Constitucional. São Paulo: Malheiros, 2004. 
BRASIL. Convenção sobre os Direitos das Pessoas com Deficiência. 2007. Disponível em: <http://www.planalto.gov.br/ccivil_03/_ato2007-2010/2009/ decreto/d6949.htm>. Acesso em: 15 jan.2016.

. Convenção sobre os Direitos das Pessoas com Deficiência: Protocolo Facultativo à Convenção sobre os Direitos das Pessoas com Deficiência: decreto legislativo $\mathrm{n}^{\mathrm{o}} 186$, de 09 de julho de 2008: decreto $\mathrm{n}^{\circ} 6.949$, de 25 de agosto de 2009. - 4. ed., rev. e atual. - Brasília: Secretaria de Direitos Humanos, Secretaria Nacional de Promoção dos Direitos da Pessoa com Deficiência, 2011. Disponível em: <http://www.pessoacomdeficiencia.gov.br/app/sites/default/files/publicacoes/convencaopessoascomdeficiencia.pdf $>$. Acesso em: 12 jan.2016.

. Emenda Constitucional No 1. 1969. Disponível em: <http://www. planalto.gov.br/ccivil_03/Constituicao/Emendas/Emc_anterior1988/emc0169.htm>. Acesso em: 01 fev.2016.

. Emenda Constitucional No 12. 1978. Disponível em: <http://www. planalto.gov.br/ccivil_03/Constituicao/Emendas/Emc_anterior1988/emc1278.htm>. Acesso em: 01 fev.2016.

. Lei Brasileira de Inclusão (LBI) ou Estatuto da Pessoa com Deficiência. 2015. Disponível em: <http://www.planalto.gov.br/ccivil_03/_ Ato2015-2018/2015/Lei/L13146.htm> Acesso em: 13 jan.2016.

. Lei Orgânica da Assistência Social. 1993. Disponível em: <http:// www.planalto.gov.br/ccivil_03/LEIS/L8742.htm> Acesso em: 15 jan.2016.

Constituição da República Federativa do Brasil. 1988. Disponível em: $\quad<$ http://www.planalto.gov.br/ccivil_03/Constituicao/Constituicao.htm> Acesso em: 13 jan.2016.

GOMES DA SILVA, L. Portadores de deficiência, igualdade e inclusão social: a dignidade da pessoa humana. In: Âmbito Jurídico. Rio Grande, XV, n.99, 2012. Disponível em: <http://www.ambito-juridico.com.br/site/?n link=revista_artigos_leitura\&artigo_id=11413>. Acesso em 01 fev.2016.

GONÇALVES, N. L. Excepcionais. In: Enciclopédia jurídica, v. 34, São Paulo: Saraiva, 2003. 
JUSBRASIL. Estimativa aponta que número de brasileiros homossexuais já chega a 17,9 milhões. 2009. Disponível em: <http://espaco-vital.jusbrasil. com.br/noticias/145829/estimativa-aponta-que-numero-de-brasileiros-homossexuais-ja-chega-a-17-9-milhoes>. Acesso em 10 ago.2016.

LUCHI, J.P. Tensão entre autonomia privada e pública. Revista de Informação Legislativa. Brasília/DF, v. 47, n. 185, p. 57-69, 2010.

LUNARDI, S.R.G.; COELHO, T.C.C. As incompatibilidades e incoerências da proteção constitucional da dignidade da pessoa humana e da Lei de Reserva de Mercado para Pessoas Portadoras de Deficiência. p. 469-492. In: ARAUJO, Luiz Alberto David (Coord). Direito da pessoa portadora de deficiência: uma tarefa a ser completada. Bauru: EDITE, 2003.

NAPOLITANO, C.J. Direito fundamental à proteção e à integração social da pessoa com deficiência à luz do texto constitucional. In: CAPELLINI, V.L.M.F.; RODRIGUES, O.M.P.R. Marcos históricos, conceituais, legais e éticos da educação inclusiva. Bauru-SP: Unesp, 2010.

OMOTE, S. Perspectivas para conceituação de deficiências. 1994. Disponível em: <http://www.abpee.net/homepageabpee04_06/artigos_em_pdf/revista4numero1pdf/r4_art11.pdf>. Acesso em: 13 jan.2016.

ONU. Carta das Nações Unidas ou Carta de São Francisco. 1945. Disponível em: <http://www.planalto.gov.br/ccivil_03/decreto/1930-1949/d19841. htm>. Acesso em: 15 jan. 2016.

ROCHA, C. L. A. Direito de todos e para todos. Belo Horizonte: Fórum, 2004.

SANTOS, Y.B.S.; OLIVEIRA, E.G. O princípio da igualdade e a pessoa com deficiência. Revista de Ciências Humanas. Volume 11. n. 2, p.429-440, 2011. Disponível em: <http://www.cch.ufv.br/revista/pdfs/artigo5evol11-2. pdf>. Acesso em: 01 fev. 2016.

SASSAKI, R.K. Como chamar as pessoas que têm deficiência? In. Revista da Sociedade Brasileira de Ostomizados, ano I, n. 1, $1^{\circ}$ sem. 2003, p. 8-11. Disponível em: <http://www.planetaeducacao.com.br/portal/artigo. asp?artigo $=1855>$. Acesso em: 08 ago. 2016. 
SEGALLA, J.I.S.F.; ARAUJO, L.A.D. A utilização do novo conceito de pessoa com deficiência: uma advertência necessária. Revista Direitos Fundamentais \& Justiça. Ano 6. n.19, p.145-159, 2012.

\section{Dados do Autor}

\section{Wellington Anselmo Martins}

Mestrando pela Universidade Estadual Paulista (Unesp) em ciências sociais aplicadas, área de Comunicação; graduado com licenciatura plena em Filosofia (USC); bolsista de pós-graduação (Capes).

am.wellington@hotmail.com 